\title{
Reseña
}

\section{Memoria y olvido: usos públicos del pasado en Colombia, 1930-1960}

\author{
Rodríguez A., Sandra Patricia. Memoria y olvido: usos \\ públicos del pasado en Colombia, 1930-1960. Bogotá: \\ Universidad del Rosario; Universidad Nacional de \\ Colombia, 2017. 480 p.
}

Juan Carlos Villamizar ${ }^{1}$

El libro de Sandra Rodríguez es una invitación a repensar nuestro pasado como colombianos. Muestra una muy rigurosa investigación acerca de la construcción de la memoria oficial que realizó la Academia Colombiana de Historia (АСН) entre 1930 y 1960. Esta pesquisa nos acerca a la verdad de la historia construida por los miembros de la Academia, es decir, el propósito adelantado por las élites conservadoras de la primera mitad del siglo $\mathrm{xx}$, de construir una memoria oficial de la historia política y social de nuestro país anterior a dicho periodo. Para la ACH se trataba de una historia tradicional, episódica, épica, patriótica y unilineal, la cual favoreció el consenso entre los partidos liberal y conservador. Era una historia inspirada en el empirismo y el positivismo. La $\mathrm{ACH}$, como estrategias para forjar dicha memoria, empleó las conmemoraciones patrióticas, la enseñanza de la historia y la conservación del patrimonio.

En cuatro capítulos, la autora estudia la conformación de la ACH, sus dinámicas institucionales, las políticas de la memoria, los olvidos y los revisionismos promovidos (en conmemoraciones, la enseñanza y la conservación patrimonial), donde se consolidaron marcos, lugares y tradiciones de la memoria.

El capítulo 1 analiza la conformación de la Academia, por hombres de la élite política conservadora, aficionados a la historia, o a lo que ellos creían era o debía ser la historia; fue una institución que contó hasta 1958 con los recursos del Estado, lo que le permitió mantener una publicación periódica (Boletín de Historia y Antigüedades). Desarrolló, igualmente, un trabajo de transferencia hacia las academias regionales; y se constituyó en el ente emisor y legítimo de la memoria oficial de la República de Colombia en el periodo señalado.

1 Doctor en Historia. Universidad Nacional de Colombia. Profesor del Departamento de Historia de la Universidad Nacional. Correo electrónico: jvillamizar@unal.edu.co 
El capítulo 2, a partir del concepto de tradición inventada, describe la práctica de los festejos patrios y, a su vez, religiosos, con la misión de recordar fechas estelares y con ello inculcar valores y normas por medio de la repetición en la población. El capítulo 3 estudia la misión desarrollada por la Academia de conservar el patrimonio histórico y cultural (archivos, monumentos, iconografía patriótica y la galería de historiadores, donde, por supuesto, los propios miembros de la Academia se otorgan su lugar).

Los eventos conmemorativos ubicaron a la Iglesia en el centro de los acontecimientos, la cruz es la alegoría de la libertad y los próceres son los mártires que sacrificaron, como Cristo, su vida por nosotros; no importan sus fallos, sus ideas, sus cambios abruptos; lo importante es mantenerlos en la santidad. Por ejemplo, Bolívar como Moisés fue un destello viviente del poder divino. Con este discurso, en la primera mitad del siglo xx, la Iglesia contribuía a la defensa de su posición política como institución eclesiástica en contra de las reformas liberales. El soldado, el párroco o el misionero son objeto de monumentos para su recordación, en un acto de gratitud para con ellos. No faltó, incluso, la idea que la Iglesia era la fuente de la civilización.

El capítulo 4 trata sobre cómo la Academia fue la fuente de la enseñanza de la historia como historia patria por varias generaciones. Bajo la categoría de análisis de la memoria ejercida de Paul Ricoeur, Sandra aborda los usos públicos del pasado, la operación cognitiva de la rememoración de un acontecimiento que tuvo lugar y la memorización del aprendizaje de saberes y destrezas que se constituyen en hábitos. Así, la propuesta de la enseñanza de la historia, por parte de la Academia, se hizo bajo cuatro claves: lo que se debe saber, lo que se debe enseñar, lo que se debe recordar y, tal vez, lo más relevante, lo que se debe olvidar. Para la $\mathrm{ACH}$, lo que se debe saber y enseñar es que la historia es lineal, desde el desembarco de Colón en América hasta el ejercicio del poder por los presidentes de la República Conservadora de principios del siglo xx, pasando por la gesta de la Independencia, todos provienen de la misma raíz católica, hispanista y conservadora. La Iglesia es el centro con la cruz, y los mártires y las fuerzas armadas son una actualización del ejercito libertador. Por su parte, corresponde a los sectores populares la consigna de recibir las enseñanzas de las élites y atender lo que se debe recordar. Entre los aspectos que se deben olvidar está el 9 de abril de 1948 y, en particular, la fuerza popular de Gaitán, la masacre de las bananeras y las reformas liberales de los años 1930. Para la ACH, "la enseñanza de la historia debería incidir para que la abnegación y el renunciamiento se impusieran en el futuro como regla general” (p. 339).

Dicho esto, dos aspectos surgen luego de la lectura de la sesuda investigación que tenemos entre manos: el primero, que estamos frente a la revelación de lo que fue la historia oficial, de carácter confesional católico, orientada hacia el hispanismo, el culto patriótico y el respeto por las fuerzas armadas y las élites. Se trata de una concepción precientífica, guiada por el animismo, una pseudociencia de la historia nacional, conceptos que no usa Sandra pero que se llenan de contenido con sus páginas. El segundo aspecto, que deriva del primero, es que la historia oficial promovida por la $\mathrm{ACH}$ fue -y tal vez sigue siendo- una fábula, no en el sentido de una composición literaria que deja una enseñanza útil o moral, sino en el sentido de ser, "una ficción artificiosa con que se encubre una verdad". Sobre esos temas trata el libro. 
El texto trae dos alusiones a Eric Hobsbawn pertinentes y lapidarias. La primera: "Es esencial que los historiadores recuerden constantemente esto. Las cosechas que cultivamos en nuestros campos pueden terminar convertidas en alguna versión del opio del pueblo"; y la segunda: “... la historia mala no es historia inofensiva. Es peligrosa. Las frases que se escriben en teclados aparentemente inocuos pueden ser sentencias de muerte". El libro de Sandra aclara cómo la historia nacional elaborada por la Academia llevó a la realidad, y con lujo de detalles, las sentencias del historiador inglés. 